\title{
Two-Photon Laser-Scanning Microscopy for Single and Repetitive Imaging of Dorsal and Lateral Spinal White Matter In Vivo
}

\author{
F. NADRIGNY ${ }^{1,2^{*}}$, K. LE MEUR ${ }^{1,3^{*}}$, E. D. SCHOMBURG ${ }^{1,4}$, S. SAFAVI-ABBASI $^{5,6}$, \\ P. DIBAJ ${ }^{1}$ \\ * These authors contributed equally to this work.
}

${ }^{1}$ Max-Planck-Institute for Experimental Medicine, Göttingen, Germany, ${ }^{2}$ U862, Institut François Magendie, Bordeaux, France, ${ }^{3}$ Department of Pharmacy, Ludwig-Maximilians-University, Munich, Germany, ${ }^{4}$ Institute of Physiology, University of Göttingen, Germany, ${ }^{5}$ Department of

Neurosurgery, University of Oklahoma Health Sciences Center, Oklahoma City, USA, ${ }^{6}$ Division of Neurological Surgery, St. Joseph`s Hospital and Medical Center, Phoenix, USA

Received August 8, 2016

Accepted December 9, 2016

On-line February 28, 2017

\begin{abstract}
Summary
We developed appropriate surgical procedures for single and repetitive multi-photon imaging of spinal cord in vivo. By intravenous anesthesia, artificial ventilation and laminectomy, acute experiments were performed in the dorsal and lateral white matter. By volatile anesthesia and minimal-invasive surgery, chronic repetitive imaging up to 8 months was performed in the dorsal column through the window between two adjacent spines. Transgenic mouse technology enabled simultaneous imaging of labeled axons, astrocytes and microglia. Repetitive imaging showed positional shifts of microglia over time. These techniques serve for investigations of cellular dynamics and cell-cell interactions in intact and pathologically changed spinal tissue.
\end{abstract}

\section{Key words}

Two-photon laser-scanning microscopy •In vivo imaging • Spinal cord • White matter $\bullet$ Glia

\section{Corresponding author}

P. Dibaj, Max-Planck-Institute for Experimental Medicine, D-37075 Göttingen, Germany. E-mail: p_dibaj@yahoo.com

\section{Introduction}

Two-photon laser-scanning microscopy (2P-LSM) is an appropriate tool to image nervous tissue in vivo (Davalos et al. 2005, Kerschensteiner et al. 2005,
Kobat et al. 2009, Dibaj et al. 2010a). Time-lapse imaging is enabled by some advantages of this technique: recording of deep stacks with high z-resolution within a relatively short time course and negligible bleaching effects on simultaneously excited fluorescent proteins (FPs). The tool serves for the study of cellular dynamics and interactions in intact and pathologically changed nervous tissue (Davalos et al. 2005, Dibaj et al. 2010a, Dibaj et al. 2010b, Dibaj et al. 2011a, Nikic et al. 2011, Dibaj et al. 2012, Nishida et al. 2014, Matsumura et al. 2015). Thereby, white matter is the appropriate CNS region for studying axon-glia interactions (Nave 2010). In contrast to the grey matter, accessibility of white matter for in vivo 2P-LSM is limited in the brain. Spinal white matter with its superficial location provides an appropriate access. Here, we demonstrate techniques for in vivo imaging of dorsal and lateral spinal white matter in a single session. Repetitive 2P-LSM imaging of the spinal dorsal column has been performed after laminectomy without (Dray et al. 2009, Di Maio et al. 2011, Davalos and Akassoglou 2012) or with implantation of a chamber (Farrar et al. 2012, Figley et al. 2013) or of a glass window (Fenrich et al. 2012, Fenrich et al. 2013). Here, we demonstrate a technique for repetitive imaging of the dorsal column by minimalinvasive surgery without the need of laminectomy or implantatory procedures. 


\section{Methods}

\section{Ethics statement}

The experiments were performed according to the ethical guidelines of the national animal protection law and were authorized by the ethical committee of the State of Lower Saxony.

Mice

Adult triple-transgenic TgN(GFAPECFP)xTgH(CX3CR1-EGFP)xTgN(THY1-EYFP) mice (2-5 months of age at the beginning of the experiments) were used for the experiments. TgH(CX3CR1EGFP)xTgN(THY1-EYFP) mice were obtained by crossbreeding homozygous CX3CR1-EGFP mice, in which the expression of the green fluorescent protein EGFP in monocytes, macrophages and microglia is achieved by placement of the EGFP reporter gene into the Cx3crl locus encoding the chemokine receptor CX3CR1, with transgenic THY1-EYFP mice expressing the yellow fluorescent protein EYFP in projection neurons (Dibaj et al. 2010a). TgH(CX3CR1-EGFP)xTgN(THY1-EYFP) mice were next crossbred with GFAP-ECFP mice expressing the cyan fluorescent protein ECFP in astrocytes (Dibaj et al. 2011b). TgH(CX3CR1-EGFP), TgN(THY1-EYFP) and TgN(GFAP-ECFP) mice were of
C57B16 background for more than 10 generations.

Anesthesia in acute single experiments

Anesthesia was initiated by $80 \mathrm{mg} / \mathrm{kg}$ pentobarbital injected i.p. The mouse was placed on a support heated by a flat pad (Fig. 1). After cannulation of the jugular vein by a catheter with an outer diameter of $0.61 \mathrm{~mm}$ (Fig. 2), anesthesia was continued intravenously with 40-60 mg methohexital-sodium per $\mathrm{kg}$ and $\mathrm{h}$. A tracheotomy was performed and a tube inserted for artificial ventilation (Fig. 2). Active respiratory movements were abolished by paralysis with pancuronium $(800 \mu \mathrm{g}$ per $\mathrm{kg}$ supplemented i.p. every hour) and artificial ventilation was performed with a gas mixture of $\mathrm{CO}_{2}(2.5 \%), \mathrm{O}_{2}(47.5 \%)$, and $\mathrm{N}_{2}(50 \%)$ at 120 strokes/min (120-160 $\mu \mathrm{l} /$ stroke depending on the weight). Rectal body temperature, heart rate (ECG: platinum wires of $0.3 \mathrm{~mm}$ diameter inserted into both forelegs and connected via a differential amplifier with an oscilloscope) and $\mathrm{O}_{2}$ blood saturation (MouseOx ${ }^{\circledR}$, Starr Life Sciences, Oakmont, USA) were continuously monitored. Appropriate dose of anesthesia was initially established by the absence of corneal and pinna reflexes, later after paralysis, by falling body temperature and heart rate.
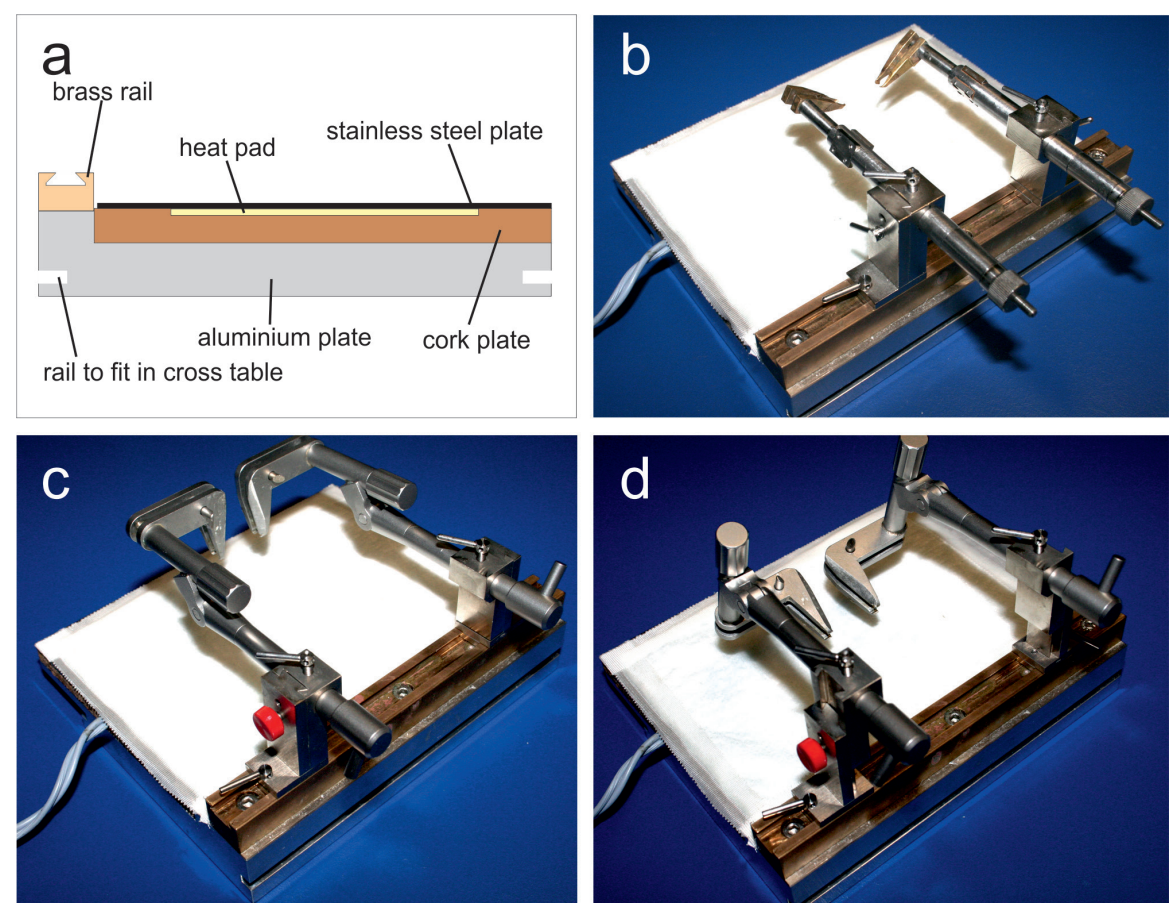

Fig. 1. Equipment for fixation of the mouse during surgery and imaging. (a) Profile of the heatable mouse support with rails to fit in the cross table of the microscope and rails to fix the vertebral column clamps. The stainless steel plate is isolated by cork to heat up only the steel plate via the heat pad. (b-d) Mouse support, covered with water proof pad, and clamps for fixation of the vertebral column. (b) Modified Narishige clamps for the vertebral column, used for the dorsal aspect of the spinal cord. The jaws are tilted to leave enough room for the Microscope lens (Fig. 3a). (c, d) Two other custommade clamps for the vertebral column, used for the lateral aspect of the spinal cord. (c) Position of the jaws during fixation of the vertebral column. (d) Position of the jaws after tilting the vertebral column for imaging lateral spinal cord. 


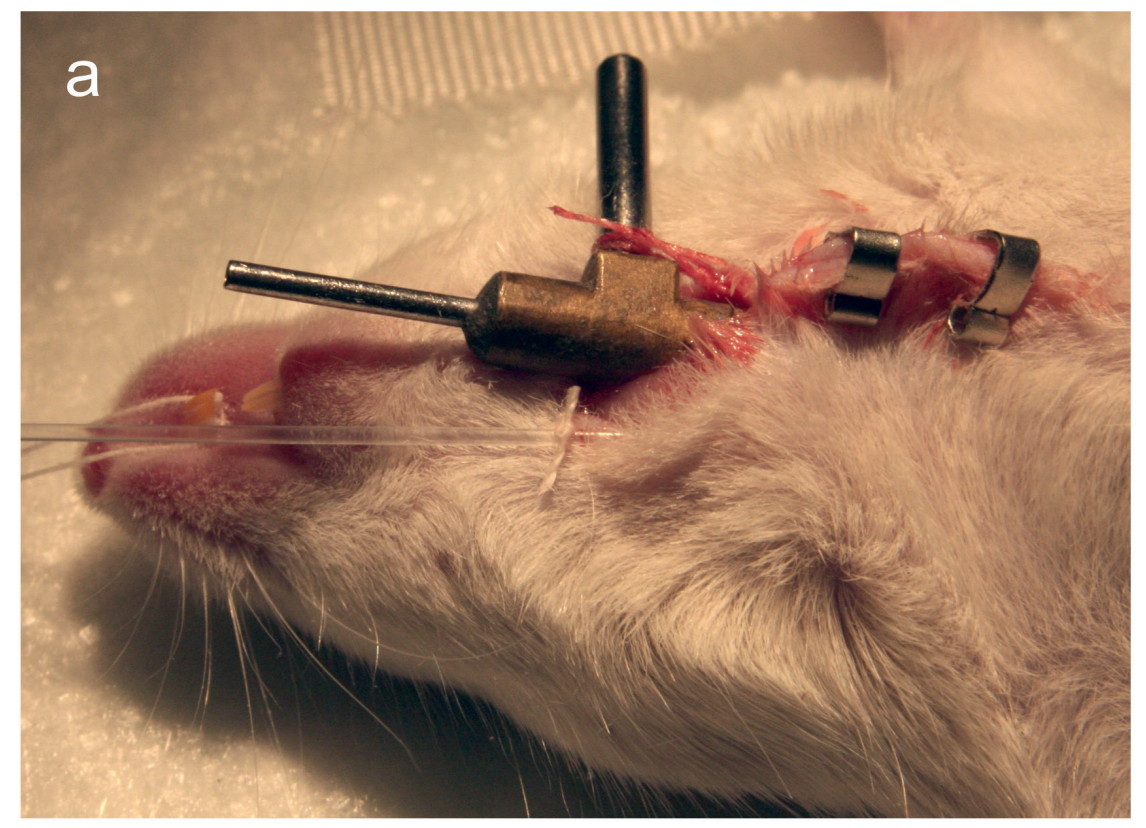

Fig. 2. Infusion anesthesia and artificial ventilation. (a) Ventral aspect of the mouse neck, with central vein catheter and tracheal tube. (b) Diagram of respiration gas flow during artificial respiration.

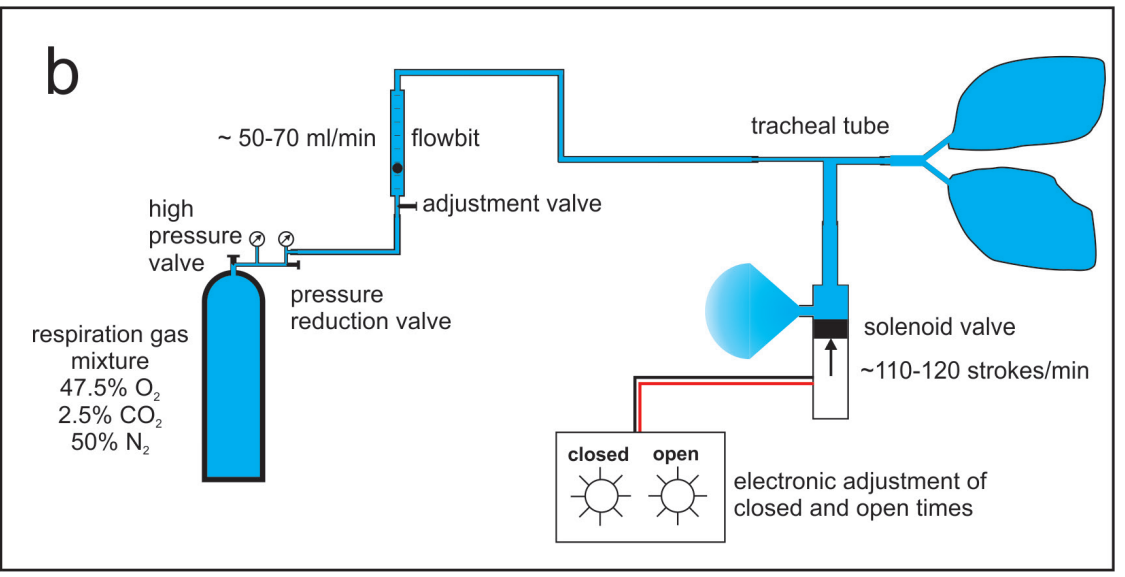

\section{Anesthesia in chronic repetitive experiments}

After initial anesthesia in a box filled with a mixture of gas $\left(1: 1 \quad \mathrm{O}_{2}: \mathrm{N}_{2} \mathrm{O} ; 1,000 \mathrm{ml} / \mathrm{min}\right)$ enriched with $5 \%$ isoflurane, the mouse was placed on the heated support and anesthesia was continued via a mask. Gas flow was reduced to $200 \mathrm{ml} / \mathrm{min} \mathrm{O}_{2}$ and $150 \mathrm{ml} / \mathrm{min} \mathrm{N}_{2} \mathrm{O}$ which was enriched with $2 \%$ isoflurane. Appropriate dose of anesthesia was established by the absence of corneal and pinna reflexes as well as by falling respiratory rate. Rectal body temperature was continuously monitored.

\section{Spinal preparation for single experiments}

After incision of the skin and removal of tendons and muscle tissue from the lumbar dorsal spinal processes and spinal arcs, a laminectomy was performed from vertebrae L1 to L4 or L5 to expose the spinal cord segments L2 to L4 as well as to expose the dorsal roots L3 to L5. For imaging purposes of the lateral spinal cord with dorsal root ganglia and ventral roots (Dibaj et al. 2011a,
Dibaj et al. 2011b, Dibaj et al. 2012), spinal arcs of the corresponding vertebral bodies were removed on one side. After paralysis, dura mater was removed if required for drug application (Dibaj et al. 2010a, Dibaj et al. 2012).

\section{Spinal preparation for repetitive experiments}

After removal of tendons and muscle tissue in the cleft between vertebral arcs L1 and L2, imaging was performed through the cleaned intact dura mater. After imaging, the wound was sutured, and $1 \mu \mathrm{g}$ buprenorphine was given twice daily s.c. for two days. Without the need of removal of spinal arcs by this procedure no signs of disability were observed between the experiments.

\section{Mounting the vertebral column}

For imaging sessions nearly free of motion artefact the vertebral column was rigidly fixed with two custom-made clamps (Fig. 1 and 3a). For imaging of the lateral spinal cord two other custom-made clamps were used to tilt the mouse up to $90^{\circ}$ (Fig. 1c, d). 

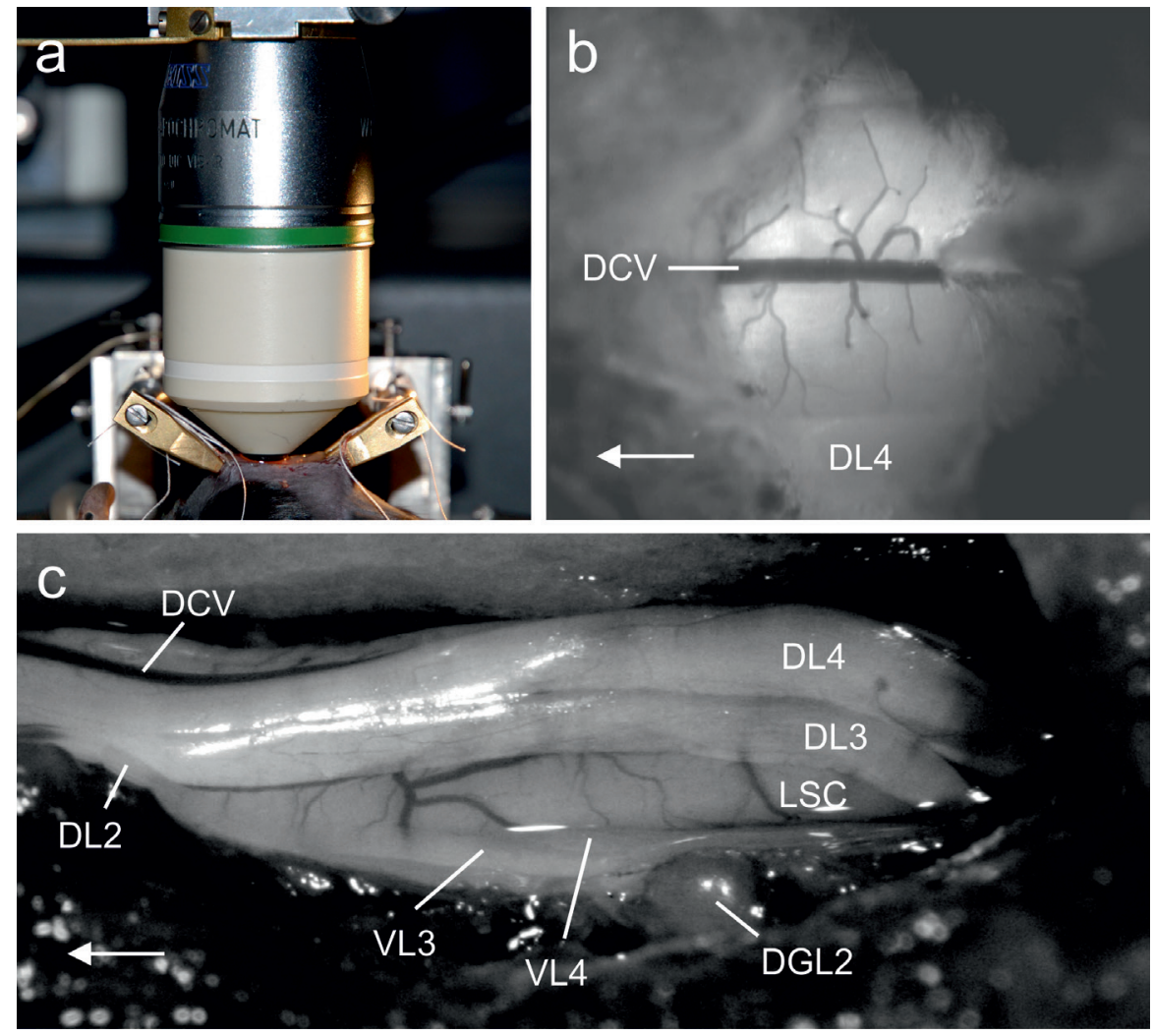

Fig. 3. Mounted vertebral column with spinal cord ready for microscopy. (a) Vertebral column fixed by clamps; objective lens in position. (b) Dorsal aspect of the spinal cord; view through the cleft between lumbar spines 1 and 2; dura intact. (c) Lateral aspect of the spinal cord; spinal arcs L1 to L3 dorsally and on the left side completely removed; dorsal roots L3 and L4 shifted dorsally. Arrows show rostrally. DCV: dorsal central vein, DGL: lumbar dorsal root ganglion, DL: lumbar dorsal root, LSC: lateral spinal cord, VL: lumbar ventral root; the numbers correspond to the lumbar spinal cord segments.
Two-photon laser-scanning microscopy and image acquisition

For 2P-LSM we built a custom-made microscope with four channels for simultaneous recording of different FPs. Three dichroic mirrors split the fluorescence signal between a Zeiss W Plan Apochromat objective (20x, NA 1.0, water immersion; Carl Zeiss GmbH, Jena, Germany) and four Photo Multiplier Tubes (Hamamatsu, Japan). Modified ScanImage software (Pologruto et al. 2003) was used to drive the microscope. Photographic and epifluorescence overviews of the spinal cord were acquired using a $5 \mathrm{x}$ objective (NA 0.15; Zeiss, Jena, Germany) and a CCD camera (Fig. 3b, c). High resolution in vivo imaging was performed using the custom-made microscope equipped with a fs-pulsed titanium-sapphire laser (Chameleon Ultra II; Coherent, Glasgow, UK). For simultaneous excitation of all FPs, the laser wavelength was set to $925 \mathrm{~nm}$ (Bestvater et al. 2002, Spiess et al. 2005). Parallel, uniformly spaced planes were recorded, digitized and processed to obtain $z$-stacks of images. The total acquisition time for a stack of 20 to 30 images and 40 to $60 \mu \mathrm{m}$ depth was approximately $2 \mathrm{~min}$. In acute experiments, several stacks were taken continuously to record time-lapse series (Dibaj et al. 2010a, Dibaj et al. 2011a).

\section{Results and Discussion}

\section{In vivo imaging of the spinal cord}

Due to high penetration depth and low phototoxicity 2P-LSM is the method of choice for in vivo imaging. We developed a method for stable in vivo imaging of superficial regions within the white matter of the spinal cord. Figure 3 exemplarily shows a dorsal and a lateral aspect of exposed spinal cords. Anesthesia and spinal preparation with respect to acute single and chronic repetitive imaging experiments are described in detail in "Methods".

Position permanence of simultaneously recorded spinal axons, astrocytes and microglia

To image axons and glia in CNS white matter, we performed in vivo 2P-LSM of the spinal cord of multiple-transgenic mice expressing ECFP, EGFP and EYFP in astrocytes, microglia and projection neurons, respectively. Long-term repetitive imaging of the same region in the dorsal spinal cord over more than 200 days revealed different spatial stability over time for axons, astrocytes and microglia (Fig. 4). Axonal structures as well as blood vessels show stable spatial stability during the complete investigation period and, therefore, served as landmarks for repetitive imaging of the same region. 
Astrocytes show a relatively high positional stability with a "positional shift half time" (time by which half of the imaged cells changed their position) of around 130 days, whereas microglial cells often change their position.
Thereby, the "positional shift half time" of perivascular microglia (around 36 days) is distinctively higher than that of parenchymal microglia (around 1.6 days).
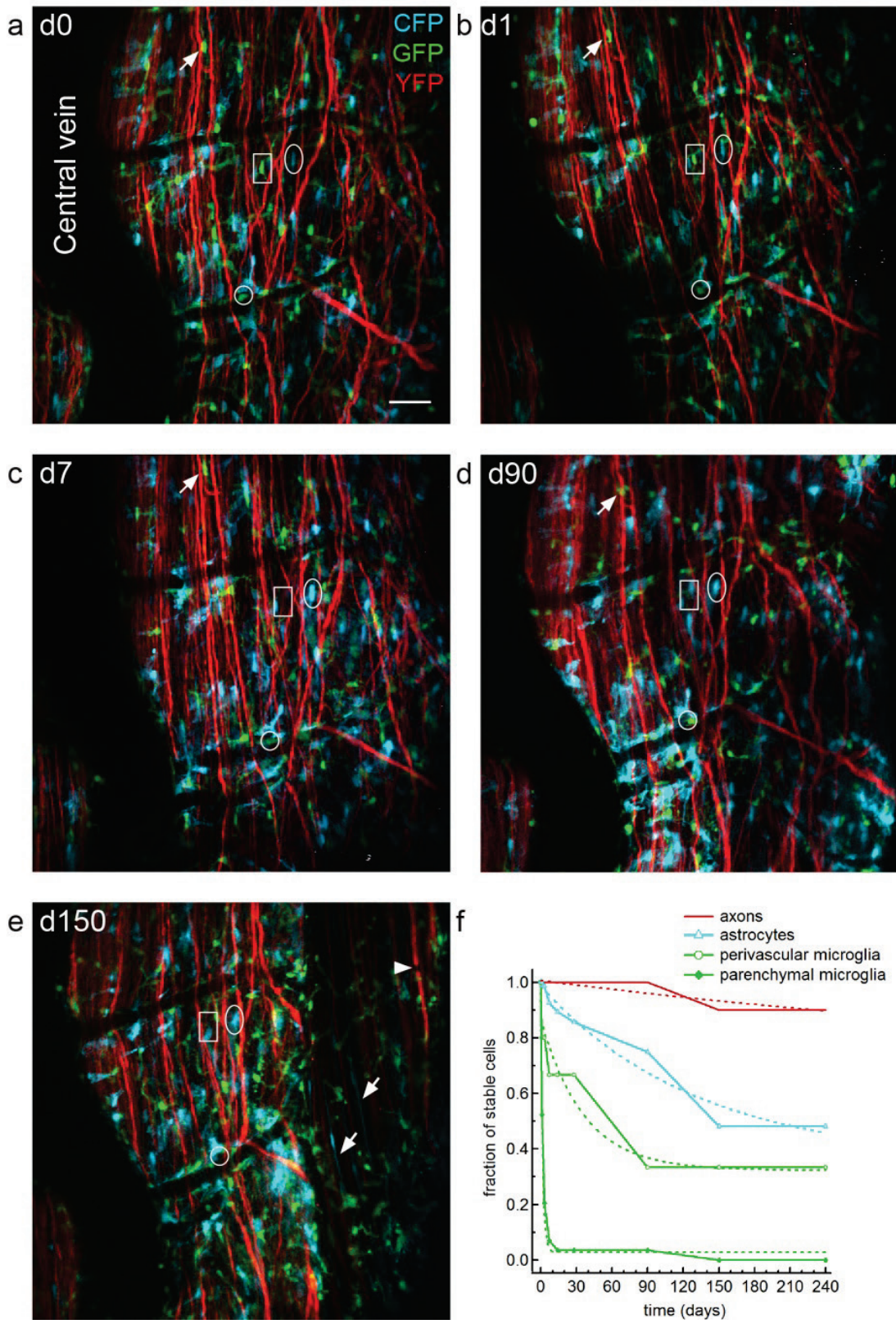

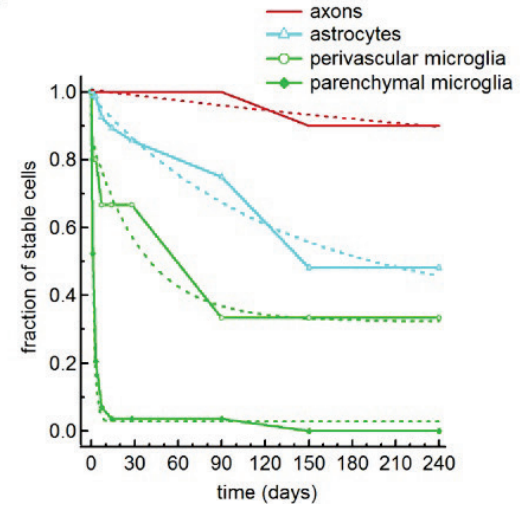

Fig. 4. Long-term repetitive multicellular imaging of the dorsal spinal cord. (a-e) Repetitive 2P-LSM images of the same region in the dorsal white matter of the lumbar spinal cord over 150 days in a triple transgenic mouse expressing ECFP in astrocytes, EGFP in microglia and EYFP in axons. Each image is a Maximum Intensity Projection of a $40-\mu \mathrm{m}$ thick stack. The central vein is on the left side, the dorsal root entry zone on the right. All images are arranged such that rostral is to the upper side. Axons are stable structures and are used as landmarks for repetitive imaging. The ellipse marks an astrocyte which is visible in all images, whereas a parenchymal microglia in the neighborhood, marked by a square, is only shortly present in the imaged stack. In contrast, another microglia, marked by an arrow in a-d, is present over a relatively long period. A perivascular microglia, marked by a circle, is also present over a relatively long period. Arrows in e mark elongated bi-polarized astro-cytes. The arrowhead marks a node of Ranvier in e. Scale bar, $50 \mu \mathrm{m}$. (f) Measuring the fraction of cells remaining at the same place over time revealed the spatial stability of each cell type over time. Although astrocytes show a relatively high positional stability ("positional shift half time" Tastro $\sim 130$ days), parenchymal microglia changed position at a very fast rate ( $T_{\text {micro }} \sim 1.6$ days). Respective half time of perivascular microglia laid in between ( $T_{\text {perivasc. micro }}$ 36 days).
A major problem during in vivo imaging of the spinal cord is the drift of the imaged area mainly due to motion artifacts resulting from the neighborhood of the spine to the lungs. Anesthesia by i.p. injection of ketamine, xylazine and acepromazine together with suspending the whole mouse in the air has been suggested to overcome respiratory movements (Davalos and Akassoglou 2012). In the presented chronic repetitive experiments using volatile anesthesia, also used by Farrar et al. (Farrar et al. 2012, Farrar et al. 2015), suspending of the mouse was not necessary thus facilitating permanent contact to the heated support. The method of imaging the spinal cord through the window between two adjacent spines distinctly minimizes not only the trauma during surgery when compared with exposure by laminectomy but also the rate of artificial movements. By the presented minimal-invasive surgical protocol, without any implantatory procedures, we were able to perform 
longitudinal studies over more than 200 days with up to ten separate imaging sessions in the same mouse without any observations of motor or other behavioral deficits.

For the performance of acute single experiments we recommend i.v. anesthesia together with intubation and artificial respiration. The animals can hereby be paralyzed which lead to a distinct reduction of active contraction-induced movements. Moreover, the respiration trigger might be used as imaging trigger leading to further reduction of motion artefacts. To our knowledge, we are the only group being able to image lateral white matter of the spinal cord in vivo (Dibaj et al. 2011a, Dibaj et al. 2011b, Dibaj et al. 2012). In this approach, for surgical and imaging purposes, motion artifacts have to be maximally reduced by paralysis and artificial respiration. In contrast to fasciculus gracilis of the dorsal column with its ascending sensory fibers, descending motor fibers can only be imaged in vivo in the lateral white matter. This is of particular interest for imaging studies of murine disease models predominantly affecting motor areas of the central nervous system, for instance, SOD1-model of amyotrophic lateral sclerosis (Dibaj et al. 2011a, Dibaj et al. 2011b, Dibaj et al. 2012).

The demonstrated techniques for in vivo imaging of dorsal and lateral spinal white matter in a single session as well as for repetitive imaging of the dorsal column by minimal-invasive surgery without the need of laminectomy or implantatory procedures serve for preclinical studies of healthy and pathologically changed spinal cord. Using murine models of neurological disorders, imaging studies in vivo, especially those with longitudinal scheme, may help to identify effective therapeutic agents.

\section{Conflict of Interest}

There is no conflict of interest.

\author{
Abbreviations \\ 2P-LSM - two-photon laser-scanning microscopy \\ ECFP/EGFP/EYFP - enhanced cyan/green/yellow \\ fluorescent protein.
}

\section{References}

BESTVATER F, SPIESS E, STOBRAWA G, HACKER M, FEURER T, PORWOL T, BERCHNERPFANNSCHMIDT U, WOTZLAW C, ACKER H: Two-photon fluorescence absorption and emission spectra of dyes relevant for cell imaging. $J$ Microsc 208: 108-115, 2002.

DAVALOS D, AKASSOGLOU K: In vivo imaging of the mouse spinal cord using two-photon microscopy. $J$ Vis Exp 59: e2760, 2012.

DAVALOS D, GRUTZENDLER J, YANG G, KIM JV, ZUO Y, JUNG S, LITTMAN DR, DUSTIN ML, GAN WB: ATP mediates rapid microglial response to local brain injury in vivo. Nat Neurosci 8: 752-758, 2005.

DIBAJ P, NADRIGNY F, STEFFENS H, SCHELLER A, HIRRLINGER J, SCHOMBURG ED, NEUSCH C, KIRCHHOFF F: NO mediates microglial response to acute spinal cord injury under ATP control in vivo. Glia 58: 1133-1144, 2010a.

DIBAJ P, STEFFENS H, NADRIGNY F, NEUSCH C, KIRCHHOFF F, SCHOMBURG ED: Long-lasting post-mortem activity of spinal microglia in situ in mice. J Neurosci Res 88: 2431-2440, 2010 b.

DIBAJ P, STEFFENS H, ZSCHÜNTZSCH J, NADRIGNY F, SCHOMBURG ED, KIRCHHOFF F, NEUSCH C: In vivo imaging reveals distinct inflammatory activity of CNS microglia versus PNS macrophages in a mouse model for ALS. PLoS One 6: e17910, 2011a.

DIBAJ P, STEFFENS H, ZSCHÜNTZSCH J, KIRCHHOFF F, SCHOMBURG ED, NEUSCH C: In vivo imaging reveals rapid morphological reactions of astrocytes towards focal lesions in an ALS mouse model. Neurosci Lett 497: 148-151, $2011 \mathrm{~b}$.

DIBAJ P, ZSCHÜNTZSCH J, STEFFENS H, SCHEFFEL J, GÖRICKE B, WEISHAUPT JH, LE MEUR K, KIRCHHOFF F, HANISCH UK, SCHOMBURG ED, NEUSCH C: Influence of methylene blue on microglia-induced inflammation and motor neuron degeneration in the SOD1 (G93A) model for ALS. PLoS One 8: e43963, 2012.

Di MAIO A, SKUBA A, HIMES BT, BHAGAT SL, HYUN JK, TESSLER A, BISHOP D, SON Y: In vivo imaging of dorsal root regeneration: rapid immobilization and presynaptic differentiation at the CNS/PNS border. J Neurosci 31: 4569-4582, 2011. 
DRAY C, ROUGON G, DEBARBIEUX F: Quantitative analysis by in vivo imaging of the dynamics of vascular and axonal networks in injured mouse spinal cord. Proc Natl Acad Sci U S A 106: 9459-9464, 2009.

FARRAR MJ, BERNSTEIN IM, SCHLAFER DH, CLELAND TA, FETCHO JR, SCHAFFER CB: Chronic in vivo imaging in the mouse spinal cord using an implanted chamber. Nat Methods 9: 297-302, 2012.

FARRAR MJ, RUBIN JD, DIAGO DM, SCHAFFER CB: Characterization of blood flow in the mouse dorsal spinal venous system before and after dorsal spinal vein occlusion. J Cereb Blood Flow Metab 35: 667-675, 2015.

FENRICH KK, WEBER P, HOCINE M, ZALC M, ROUGON G, DEBARBIEUX F: Long-term in vivo imaging of normal and pathological mouse spinal cord with subcellular resolution using implanted glass windows. J Physiol 590: 3665-3675, 2012.

FENRICH KK, WEBER P, ROUGON G, DEBARBIEUX F: Long- and short-term intravital imaging reveals differential spatiotemporal recruitment and function of myelomonocytic cells after spinal cord injury. $J$ Physiol 591: 4895-4902, 2013.

FIGLEY SA, CHEN Y, MAEDA A, CONROY L, MCMULLEN JD, SILVER JI, STAPLETON S, VITKIN A, LINDSAY P, BURRELL K, ET AL.: A spinal cord window chamber model for in vivo longitudinal multimodal optical and acoustic imaging in a murine model. PLoS One 8: e58081, 2013.

KERSCHENSTEINER M, SCHWAB ME, LICHTMAN JW, MISGELD T: In vivo imaging of axonal degeneration and regeneration in the injured spinal cord. Nat Med 11: 572-577, 2005.

KOBAT D, DURST ME, NISHIMURA N, WONG AW, SCHAFFER CB, XU C: Deep tissue multiphoton microscopy using longer wavelength excitation. Opt Express 17: 13354-13364, 2009.

MATSUMURA S, TANIGUCHI W, NISHIDA K, NAKATSUKA T, ITO S: In vivo two-photon imaging of structural dynamics in the spinal dorsal horn in an inflammatory pain model. Eur J Neurosci 41: 989-997, 2015.

NAVE KA: Myelination and support of axonal integrity by glia. Nature 468: 244-252, 2010.

NIKIC I, MERKLER D, SORBARA C, BRINKOETTER M, KREUTZFELDT M, BAREYRE FM, BRUCK W, BISHOP D, MISGELD T, KERSCHENSTEINER M: Reversible form of axon damage in experimental autoimmune encephalomyelitis and multiple sclerosis. Nat Med 17: 495-499, 2011.

NISHIDA K, MATSUMURA S, TANIGUCHI W, UTA D, FURUE H, ITO S: Three-dimensional distribution of sensory stimulation-evoked neuronal activity of spinal dorsal horn neurons analyzed by in vivo calcium imaging. PLoS One 9: e103321, 2014.

POLOGRUTO TA, SABATINI BL, SVOBODA K: ScanImage: flexible software for operating laser scanning microscopes. Biomed Eng Online 2: 13, 2003.

SPIESS E, BESTVATER F, HECKEL-POMPEY A, TOTH K, HACKER M, STOBRAWA G, FEURER T, WOTZLAW C, BERCHNER-PFANNSCHMIDT U, PORWOL T, ACKER H: Two-photon excitation and emission spectra of the green fluorescent protein variants ECFP, EGFP and EYFP. J Microsc 217: 200-204, 2005. 